\title{
Saúde e consumo: o hospital como lugar de produção de identidade
}

\author{
Health and consumption: the hospital as a place of \\ identity production
}

http://dx.doi.org/10.5007/2178-4582.2017v51n1p213

\author{
Kassia de Oliveira Martins Siqueira \\ Universidade do Estado do Rio de Janeiro/RJ, Brasil
}

\begin{abstract}
O objetivo deste artigo é problematizar a relação entre saúde e consumo na política pública de saúde. A metodologia utilizada é a pesquisaintervenção, ferramenta da análise institucional, em que a pesquisa realiza-se a partir das experiências vividas pelo próprio pesquisador. Como resultado da problematização das minhas vivências na área da saúde, destaco a importância da compreensão das relações de poder que atravessam o cotidiano hospitalar, no sentido de desnaturalizar a lógica da saúde instituída como dever, possibilitando pensála de modo filosófico para além das práticas que vinculam saúde e consumo.
\end{abstract}

Palavras-chave: saúde; consumo; identidade; resistência.
The purpose of this article is to discuss the relationship between health and consumption in public health policy. The methodology used is the intervention research, institutional analysis tool, in which research is carried out from the experiences of the researcher. As a result of questioning of my experiences in health, emphasize the importance of understanding the power relations involved in the daily hospital routine, to deconstruct the logic of health established as a duty, making it possible to think of it in a philosophical way beyond practices that link health and consumption.

Keywords: health; consumption; identity; strength.

\section{Introdução}

\begin{abstract}
Estamos envoltos numa severa malha de deveres e dela não podemos sair-nisso precisamente somos também nós, "homens do dever"! Ocasionalmente, é verdade, dançamos com nossas "cadeias" e entre nossas "espadas"; com mais freqüência, não é menos verdade, gememos debaixo delas e somos impacientes com toda a secreta dureza do nosso destino. (NIETZSCHE, 2005, p. 118)
\end{abstract}

Em um mês de dezembro no hall de entrada de um hospital de câncer situado no Rio de Janeiro, encontrava-se uma grande árvore de natal enfeitada com luzes pisca-pisca e laços vermelhos, contrastando com o cheiro de hospital e com o frio que aquele ambiente costuma provocar.

Nos corredores, pessoas passavam de um lado para o outro. Adultos e crianças. Muitos sem cabelo, alguns com feridas no rosto e pescoço, cobertas com curativos grandes e pequenos. Passavam também muitos profissionais 
usando roupas brancas - já que é obrigatório o uso de jaleco branco para grande parte dos que atuam na assistência aos "pacientes".

Foi nesse cenário que passei a atuar como assistente social, quando fui transferida, por solicitação minha, de outra unidade hospitalar pertencente a esse mesmo hospital, que tratava apenas de pessoas com câncer de mama. Cenário parecido com o que eu atuava antes, mas que se mostra ainda mais triste pela presença constante de crianças com expressão de sofrimento ou em cadeira de rodas, usando muletas e mesmo com partes de seus corpos amputados.

"A árvore de natal certamente está ali por causa delas...", pensei durante o mês de dezembro. No hospital de adultos em que eu atuava antes, não havia uma árvore grande como aquela. E no hall do $5^{\circ}$ andar, onde as crianças permanecem internadas, havia no chão uma cobertura de tecido imitando neve, com uma arvore colorida por cima, um cercadinho em volta e diversos e pequenos brinquedos espalhados pelo chão.

Apesar de aparentemente ser esse o objetivo, a presença da árvore de natal parece não ter deixado o ambiente alegre, ao contrário, acentuou a tristeza, pois fazia lembrar que mesmo sendo o fim do ano, momento em que se dá o auge do consumo e em que se propagam os ideais - pautados em modelos - de vida, saúde, felicidade, longevidade e família, havia pessoas doentes e morrendo. E elas eram crianças.

Aquelas crianças não estavam consumindo comidas natalinas ou outras coisas que crianças consumiam naquele período do ano, mas elas consumiam saúde, no que se define atualmente como saúde em um modelo institucionalizado. Nesse contexto, elas não eram apenas crianças, mas também "pacientes".

Assim, os "pacientes" - crianças e adultos - internados nesse hospital em dezembro, estavam submetidos ao tratamento oncológico, em uma rotina em que o espaço físico se divide em alas, leitos, medicações, cadeiras de rodas e higiênicas, poltronas para acompanhantes, salas de cirurgia, postos de enfermagem, uniformes brancos, quartos com janelas fechadas cobertas por película escurecida que muitas vezes inviabiliza até mesmo a entrada da luz do sol.

$\mathrm{O}$ ar condicionado frio em demasia ressalta a rigidez do ambiente, justificado pelo medo de infecção. O odor constante em algumas alas é muito intenso e a cor branca e bege das paredes da maioria dos quartos e das escadas contribuía para a falta de alegria e potência no hospital, que muitas vezes parecia hostil: sem cor, sem calor.

A preocupação com os registros e a relevância que a disciplina tem no cotidiano hospitalar parece substituir a força das relações que poderiam se dar 
entre pessoas que vivenciam momentos tão importantes e marcantes em suas vidas, momentos de mudança, de dor, de transformação.

É nesse contexto que pensar a relação entre saúde e consumo tornase fundamental, no sentido de questionar também as relações de poder no hospital, local que costuma ser afirmado como de "saúde", ainda que suas práticas em muitos momentos neguem a possibilidade de afirmação de uma vida saudável que não se afirma por normas, modelos e padronizações.

Nesse sentido, este artigo pretende pensar o hospital enquanto local de produção de identidade, problematizando as práticas de saúde e sua relação com a lógica do consumo na sociedade capitalista. Pretende ainda questionar o hospital afirmado como lugar da salvação e da cura, pensando nas relações que afirmam cotidianamente a necessária obediência dos pacientes às prescrições dos profissionais de saúde, em detrimento do respeito às suas diferenças, desejos e necessidades singulares.

Como metodologia adotada para a elaboração deste artigo, utilizei as ferramentas da Análise Institucional, sendo a pesquisa-intervenção e a análise de implicações as principais. Para Coimbra e Nascimento (2007), os trabalhos de intervenção nos provocam a estranhar e mesmo questionar a homogeneidade, a coerência, a naturalidade dos objetos e dos sujeitos que estão no mundo. Ao mesmo tempo, afirmar as multiplicidades, as diferenças, a potencialidade dos encontros que são sempre coletivos e a produção histórica desses mesmos objetos e sujeitos .

Por outro lado, a Análise Institucional propõe como método a análise de nossas implicações, sendo esta "uma forma de pensar, cotidianamente, como vêm se dando nossas diferentes intervenções" (COIMBRA; NASCIMENTO, 2005 p. 3). Para as autoras, dentro de uma visão positivista que afirma a objetividade e a neutralidade do pesquisador, as propostas da Análise Institucional tornam-se, efetivamente, uma subversão. Colocar em análise o lugar que ocupamos, nossas práticas de saber-poder enquanto produtoras de verdades - consideradas absolutas, universais e eternas - seus efeitos, o que elas põem em funcionamento, com o que se agenciam é romper com a lógica racionalista presente no pensamento ocidental e, em especial, na Academia.

Para Lourau (1993), a história das ciências nos mostra que as implicações do pesquisador em situação de pesquisa devem ser vistas como o essencial do trabalho científico. Ele coloca que, diferente da metodologia clássica, a Análise Institucional tenta não fazer um isolamento entre o ato de pesquisar e o momento em que a pesquisa acontece na construção do conhecimento.

Scheinvar (2009) afirma que a intervenção sócio-analítica parte de um território como diagrama de forças, compreendendo-o como um campo de 
atravessamentos. Nessa perspectiva, entende-se que a produção de verdades sobre determinado assunto passa pelas relações de saber-poder e, portanto, analisar as implicações do pesquisador possibilita a problematização dessas relações que são tidas como naturais, visando desnaturalizá- las.

Assim, é com o objetivo de desnaturalizar as práticas hospitalares em um hospital de câncer, estremecendo sua aparente naturalidade, que este artigo pretende pensar a produção da identidade "paciente", muitas vezes diagnosticado como doente mental ou anormal, ao recusar procedimentos cirúrgicos ou outras intervenções médicas. Questionamos neste texto a naturalização da relação entre normalidade e obediência, entendendo como expressão das singularidades dos usuários as resistências e recusas ao tratamento oncológico.

\title{
A resistência ao tratamento de saúde frente à produção da identidade "paciente"
}

\begin{abstract}
O adestramento do corpo, o aprendizado do gesto, a regulação do comportamento, a normalização do prazer, a interpretação do discurso, com o objetivo de separar, comparar, distribuir, avaliar, hierarquizar, tudo isso faz com que apareça pela primeira vez na história a figura singular, individualizada do homem como produção do poder. Mas também, e ao mesmo tempo, como objeto de saber. Das técnicas disciplinares, que são técnicas de individualização, nasce um tipo específico de saber: as ciências do homem. (MACHADO, 2007, p. 176)
\end{abstract}

Machado (2007) aponta que Foucault chamou de "disciplina" ou "poder disciplinar" uma forma de poder que nem é um aparelho de Estado, nem uma instituição, já que funciona como uma rede que os atravessa sem se limitar às suas fronteiras. Assim, para Foucault, a disciplina é uma técnica, um dispositivo, um mecanismo, um instrumento do poder, métodos que permitem o controle minucioso das operações do corpo e que asseguram a sujeição constante de suas forças, impondo-lhes uma relação de docilidade-utilidade. Tal forma de poder não atua do exterior, mas trabalha o corpo dos homens, manipula seus elementos, produz seu comportamento, enfim, fabrica o tipo de homem necessário ao funcionamento e manutenção da sociedade industrial, capitalista (MACHADO, 2007).

Uma das características mais importantes da disciplina é a organização do espaço, sendo uma técnica de distribuição dos indivíduos através da inserção dos corpos em espaço individualizado, classificatório, combinatório, em que o indivíduo é isolado em um espaço fechado, esquadrinhado, hierarquizado, 
capaz de desempenhar funções diferentes segundo o objetivo específico que dele se exige. Outra característica da disciplina é um controle do tempo, estabelecendo a sujeição do corpo ao tempo, com o objetivo de estabelecer o máximo de rapidez e o máximo de eficácia. Neste sentido, não é o resultado da ação que lhe interessa, mas sim o seu desenvolvimento.

A vigilância é um dos principais instrumentos de controle da disciplina. Não uma vigilância fragmentar e descontínua, mas contínua, perpétua, permanente; uma vigilância sem limites, que penetra nos lugares mais recônditos e está presente em toda a extensão do espaço, sendo um [...] "olhar invisível - como o do Panopticon de Bentham, que permite ver tudo permanentemente sem ser visto - que deve impregnar quem é vigiado, de tal modo que este adquira de si mesmo a visão de quem o olha" (MACHADO, 2007, p. 173-174).

Assim, a disciplina é, antes de tudo, uma prática. Segundo Fischer, tudo é prática em Foucault e tudo está imerso em relações de poder e saber, que se implicam mutuamente. Assim, os enunciados, textos e instituições, assim como o ato de falar e ver, [...] "constituem práticas sociais por definição permanentemente presas, amarradas às relações de poder, que as supõem e as atualizam" (FISCHER, 2012, p. 75).

Para a autora, o discurso ultrapassa a simples referência a coisas, existindo para além da mera utilização de letras, palavras e frases, não podendo ser entendido apenas como um fenômeno de mera "expressão" de algo, visto que [...] "apresenta regularidades intrínsecas a si mesmo, através das quais é possível definir uma rede conceitual que lhe é própria” (FISCHER, 2012, p. 75). Nesse sentido, o discurso, a formação discursiva, deve ser vista.

\footnotetext{
antes de qualquer coisa, como o "princípio de dispersão e repartição" dos enunciados segundo o qual se "sabe" o que pode e o que deve ser dito, dentro de um determinado campo e de acordo com uma certa posição que se ocupa nesse campo. Ela funcionaria como uma "matriz de sentido", e os falantes nela se reconheceriam, porque as significações ali lhes parecem óbvias, "naturais". (FISCHER, 2012, p. 79)
}

Na área da saúde, mais especificamente na oncologia - sendo essa uma especialidade da medicina -, há a naturalização de discursos e práticas voltadas ao controle e à cura do câncer. Uma das práticas mais recorrentes nesse campo de atuação é a amputação de uma parte do corpo do indivíduo, quando essa está afetada pela doença. A amputação é realizada tanto em crianças como em adultos. Por ser um tratamento doloroso, nem sempre as pessoas aceitam a realização de cirurgia, que é indicada principalmente para os casos em que há perspectiva de cura da doença. 
$\mathrm{O}$ tratamento voltado às pessoas definidas como "portadoras de neoplasia maligna" é muitas vezes invasivo, gerando grande sofrimento e, em alguns casos, recusa. A quimioterapia pode provocar reações adversas, assim como a radioterapia. No caso das cirurgias, essas são, muitas vezes, mutiladoras e as "equipes de saúde", compostas por diversos profissionais - dentre eles os assistentes sociais - têm como objetivo a adesão ao tratamento por parte dos "pacientes", já que todo o trabalho desenvolvido no hospital deve visar à cura ou a minimização dos sintomas. Alguns tipos de câncer são curáveis com cirurgia, outros não.

O discurso profissional que defende a necessidade de amputação nos casos de diagnóstico de câncer em que esse procedimento é indicado, é respaldado cientificamente e seu uso tão recorrente, que pode tornar uma amputação algo familiar, "natural" para nós, os especialistas, já que são centenas de pessoas perdendo partes de seus corpos mensalmente. Segundo o sistema de planejamento de um hospital público no Rio de Janeiro, apenas no ano de 2013 foram realizadas 4.594 cirurgias somente em uma de suas cinco unidades hospitalares, o que torna essa uma prática constante em nosso cotidiano profissional, algo que acontece freqüentemente.

Na pediatria desse grande hospital público especializado em oncologia, é freqüente o diagnóstico de "Osteossarcoma" em adolescentes, um câncer que tem início na perna e se não operado há tempo, pode causar metástase pulmonar. Enquanto apenas localizado na perna e em condições de cirurgia é definido pela medicina como um câncer curável e, nesse sentido, a amputação da perna costuma ser indicada como parte do tratamento.

No entanto, pode não ser "normal" para um adolescente, por exemplo, ter sua perna amputada. Com isso, ele pode recusar o tratamento. E sua recusa nem sempre é compreendida e aceita. De acordo com minha experiência, a resistência ao tratamento pode ser vista pela equipe como mais que um não, pois colocava em questão a identidade "paciente": aquele que acata passivamente ao diagnóstico, tratamento e acompanhamento. Mas como se produziu tal identidade? Como o hospital se tornou o lugar da cura? Essas são questões importantes de serem problematizadas, já que tais práticas não são "naturais", mas uma produção, embora sejam muitas vezes afirmadas como tais.

Em alguns casos, não apenas o adolescente recusa a cirurgia, mas também a família resiste à orientação médica de obrigá-lo a realizar o procedimento cirúrgico. Neste caso, a família também pode ser questionada quanto ao seu amor pelo adolescente, seu cuidado, sua capacidade de ser pai ou mãe. Os profissionais, em alguns casos, chegam até a ameaçar os pais, afirmando a necessidade de encaminhar à justiça a recusa de seus filhos, dizendo que o juiz vai decidir se a perna do adolescente, por exemplo, deve ser amputada ou não. 
Com isso, o discurso médico, reforçado pelo discurso da lei, do direito e da "justiça", define que há algo certo e justo a ser feito, assim como a existência de alguém que estaria em uma instância superior, sendo apto a julgar a decisão dos pais de respeitar a escolha do adolescente. E, nesse contexto, a culpa por esse julgamento recai sobre o próprio paciente, sobre sua resistência ao tratamento e recusa em se submeter à cirurgia.

No entanto, enquanto profissional de saúde, entendo que optar por retirar ou não uma parte do seu corpo deve ser uma possibilidade acessível a todos, o que infelizmente não ocorre nos casos em que estão envolvidos crianças e adolescentes.

\section{Discurso médico e produção de identidade: relações de saber-poder}

O discurso médico que defende a necessidade de amputação não é um discurso errado ou cruel, mas uma produção social e histórica. O hospital tornou-se o lugar da cura, da "saúde", sendo o Estado, principalmente na figura do médico, o responsável em promovê-la, mesmo quando alguém não quer se curar, não quer se tratar, não quer viver ou quer morrer. Mesmo quando alguém faz a opção de permanecer com alguma parte do seu corpo, quando esta deve, segundo prescrição médica, ser retirada.

Mas por que todo esse interesse do Estado nos corpos das pessoas? Por que toda essa necessidade de garantir a vida, mesmo contra a vontade daquele que a possui? Como o hospital se tornou esse lugar da cura hoje tão aceita e normalizada?

De acordo com Foucault (1979), o hospital como instrumento terapêutico é uma invenção relativamente nova, que data do final do século XVIII. O autor aponta que a consciência de que o hospital pode e deve ser um instrumento destinado a curar aparece em torno de 1780 e é assinalada por uma nova prática: a visita e a observação sistemática e comparada dos hospitais.

Para Foucault, antes do século XVIII o hospital era essencialmente uma instituição de assistência aos pobres, visto que

O pobre como pobre tem necessidade de assistência e, como doente, portador de doença e de possível contágio, é perigoso. Por essas razões, o hospital deve estar presente tanto para recolhê-lo, quanto para proteger os outros do perigo que ele encarna. (FOUCAULT, 1979, p. 101)

Assim, Foucault aponta que o personagem ideal do hospital até o século XVIII não era o doente que é preciso curar, mas o pobre que está morrendo. A 
função essencial do hospital nesse período era assistir material e espiritualmente o pobre, para lhes dar os últimos cuidados e o último sacramento.

O hospital que temos hoje, segundo Foucault (1979) transformou-se no lugar da cura e foi medicalizado a partir da disciplina, que passou a ser empregada enquanto técnica voltada ao controle dos corpos e das vidas dos doentes. A justificativa para a medicalização do hospital foi a desordem que nele havia.

O primeiro fator da transformação foi não a busca de uma ação positiva do hospital sobre o doente ou a doença, mas simplesmente a anulação dos efeitos negativos do hospital. Não se procurou primeiramente medicalizar o hospital, mas purificá-lo dos efeitos nocivos, da desordem que ele acarretava. E desordem aqui significa doenças que ele podia suscitar nas pessoas internadas e espalhar na cidade em que estava situado, como também a desordem econômico-social de que era foco perpétuo. (FOUCAULT, 1979, p. 103)

Assim, há uma produção histórica do hospital enquanto lugar de recolhimento, realizado inicialmente por pessoas caridosas, em uma prática que tornava o hospital

um morredouro, um lugar onde morrer. E o pessoal hospitalar não era fundamentalmente destinado a realizar a cura do doente, mas a conseguir a sua própria salvação. Era um pessoal caritativo - religioso ou leigo - que estava no hospital para fazer uma obra de caridade que lhe assegurava uma salvação eterna. (FOUCAULT, 1979, p. 102)

Assim, o hospital federal em questão, que no ano de 2013 é identificado como lugar de promover "saúde", é diferente dos hospitais existentes anteriormente, que nem sempre tiveram essa atribuição. A lógica hospitalar antes do século XVIII era a do recolhimento e da caridade, onde se salvavam as almas tanto dos pobres que estavam morrendo, quanto daqueles que se disponibilizavam a cuidar deles. Nessa lógica, o poder pastoral perpassa o hospital desde sua origem, já que o padre ou pastor analisado nas obras de Nietzsche e Foucault conduz o rebanho e cada um individualmente e ao mesmo tempo, visando à salvação de todos e de cada um.

É importante salientar que o tipo padre na filosofia de Nietzsche (1998) - que também apareceu na obra de Foucalt (1995; 2002), quando este estudou a extensão do poder pastoral na modernidade - ultrapassa o personagem cristão específico, tal como conhecido pelo senso comum, para 
indicar uma certa psicologia, ou uma formação subjetiva característica daqueles que deseja impor seu poder sobre os outros por meio da defesa de certos valores morais, como se estes representassem a própria fonte de salvação ou da cura. (REIS, 2013, p. 20)

Desse modo, o poder pastoral já estava presente no hospital antes de sua disciplinarização e medicalização e, com a medicalização dos hospitais, as práticas em âmbito hospitalar não deixaram de ser menos pastorais.

Segundo Reis,

Para Foucalt (2002), a medicina foi uma das grandes potências hereditárias do pastorado, na medida em que tomou para si o encargo de conduzir a existência cotidiana dos homens, tomando o corpo humano como objeto e alvo do poder, na forma de um controle detalhado. Não à toa, Foucault (1979) relacionou a emergência da norma e o fortalecimento do poder de normalização às práticas médicas, e não às jurídicas, como se poderia imaginar. (REIS, 2013 p. 58)

Foucault (2012) afirma que o poder pastoral manteve um caráter essencial e singular na história das civilizações, exercendo-se como qualquer outro poder do tipo religioso ou político sobre o grupo inteiro. Essa forma de poder

(...) tem por preocupação e tarefa principal velar pela salvação de todos, apenas operando sobre cada elemento em particular, cada ovelha do rebanho, cada individuo, não somente para obrigá-lo a agir dessa ou daquela maneira, mas também de modo a conhecê-lo, a desvendá-lo, a fazer aparecer a sua subjetividade e visando a estruturar a relação que ele estabelece consigo próprio e com sua própria consciência. As técnicas da pastoral cristã, relativas à direção da consciência, ao cuidado das almas, a todas essas práticas que vão do exame à confissão passando pelo reconhecimento, essa relação obrigatória de si para consigo em termos de verdade e de discurso obrigatório, creio que ela é um dos pontos fundamentais do poder pastoral, sendo aquilo que faz dele um poder individualizante. $\mathrm{O}$ poder nas cidades gregas e no Império Romano, não tinha a necessidade de conhecer os indivíduos um a um, de constituir a respeito de cada um uma espécie de pequeno núcleo de verdade que a confissão deveria trazer à luz e que a escuta atenta do pastor deveria recolher e julgar. (FOUCAULT, 2012, p. 51)

Desse modo, o poder pastoral está presente fortemente nas práticas consideradas de "saúde" e no cotidiano hospitalar desde o início. A escuta que 
visa desvendar, conhecer, classificar, o esquadrinhamento do corpo, da vida, da subjetividade, visando a salvação, todas essas práticas estão presentes no hospital desde que passou a existir como lugar da cura e mesmo antes, quando lugar de recolhimento dos pobres. Nesse sentido, considero fundamental colocar em análise as relações de poder que perpassam a relação entre "pacientes" e profissionais de saúde, com o objetivo de analisar a naturalização de certas práticas, que são atravessadas também pela judicialização dos corpos e da vida.

Tal judicialização fica evidente no caso de um adolescente que, ao negar ter sua perna amputada, passa a ter seu corpo submetido à decisão do juiz, quando os profissionais de saúde ameaçam encaminhar o caso à justiça. Tais ameaças me fazem questionar: A que ponto chega esse controle dos corpos, essa regulamentação da vida? É possível que o Estado possa até mesmo retirar parte do corpo de uma pessoa sem que ela permita?

Meu objetivo em problematizar não é colocar os médicos como vilões, mas pensar o discurso médico enquanto produtor de "saúde" e como se deu a produção desse discurso, para que hoje seja aceito como natural.

Assim, algumas questões se colocam: O que é saúde? O que é ser saudável? É possível ter saúde nessa lógica judicializante sem seguir as orientações e prescrições médicas? Como se dão tais prescrições? Saúde e medicalização são a mesma coisa? É possível que o "paciente" possa participar ativamente em seu tratamento, a partir de suas escolhas, sendo a resistência ao tratamento considerada como uma possibilidade legítima, como algo saudável? O que é ser "paciente" de acordo com as práticas médicas e de saúde atuais?

Desse modo, problematizar a historicidade do discurso e a concepção de saúde atual, faz com que possamos problematizar o discurso de quem fala nesse caso o discurso médico - como uma produção histórica, como aponta Fischer (2012),

A pergunta "quem fala?" desdobra-se em muitas outras: qual o status do enunciador, qual a sua competência, em que campo de saber se insere, qual seu lugar institucional, como seu papel se constitui juridicamente, como se relaciona hierarquicamente com outros poderes além do seu, como é realizada sua relação com outros indivíduos no espaço ocupado por ele. Também cabe indagar sobre o "lugar de onde fala", o lugar específico no interior de uma dada instituição, a fonte do discurso daquele falante; e sobre sua efetiva "posição de sujeito" - suas ações concretas, basicamente como sujeito incitador e produtor de saberes. É assim que destrói a idéia de discurso como "expressão" de algo, tradução de alguma coisa que estaria em outro lugar, talvez em um sujeito, algo que preexiste à própria palavra. (FISCHER, 2012, p. 83) 
Com isso, não se trata de ver o médico que não aceita a recusa de um adolescente à cirurgia como bom ou mau, como certo ou errado, mas de contextualizar sua ação nas relações de saber/poder.

Ou seja, as concepções de saúde, doença, normalidade, vida, etc. são produções definidas por parâmetros pautados em um modelo de vida burguês. Não há uma concepção neutra ou uma verdade inquestionável sobre cada umas dessas concepções, como é frequentemente afirmado.

Nesse sentido, Coimbra e Nascimento (2001) apontam que,

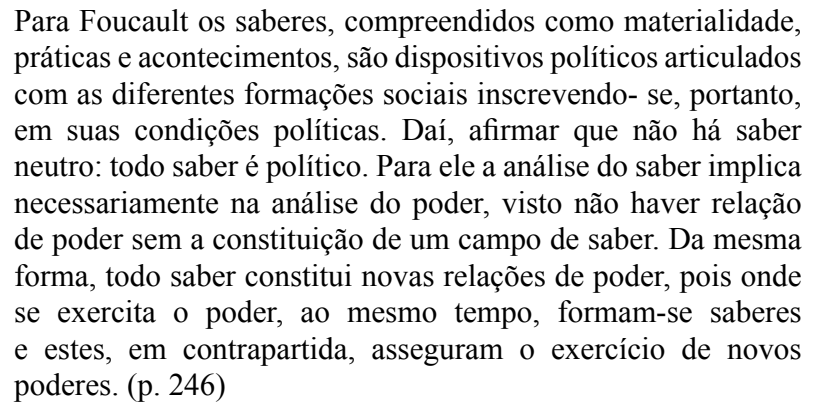

Com isso, as afirmações quanto à necessidade de amputação, e outras prescrições no tratamento oncológico, são afirmações pautadas em discursos científicos que com freqüência desqualificam outros saberes, não acadêmicos, não científicos, afirmados pelas famílias pobres, usuárias dos serviços públicos de saúde. $\mathrm{O}$ discurso médico que define a forma correta do tratamento frente ao paciente, afirma a identidade "paciente" como aquele que necessariamente deve acatar as prescrições, sendo considerado anormal quando recusa uma cirurgia, por exemplo, que poderia levá-lo à cura.

\section{Saúde, consumo e produção de identidade}

Nesse sentido, cabe também problematizar a relação entre a concepção de saúde atual e consumo: nós não somente "acessamos" saúde como geralmente é afirmado nos discursos que a defendem enquanto garantidora e possibilitadora da vida, não apenas reivindicamos por ou a negamos, mas principalmente somos consumidores de saúde, consumimos internações hospitalares, devendo ser hospitalizados em determinados momentos de nossas vidas, ainda que não o desejemos e, na maioria das vezes, por demanda nossa.

Devemos fazer os tratamentos propostos, seguindo as orientações médicas e, o maior paradoxo: temos direito à vida, mas não temos o direito à morte, se assim o desejamos. Nosso direito à vida é, na verdade, uma 
obrigação de viver. É para evitar a morte que se garante a vida, não pela vida em sua potência, enquanto uma paixão alegre. O Estado nos faz viver não para que sejamos livres, mas para que sejamos escravos, presos a uma forma de vida que nos separa de nossa potência de criar, agir, desejar. Como afirma Fuganti,

\begin{abstract}
Pertence à própria natureza do Estado este modo de codificar seus membros pela relação de obediência e transgressão. É por isso que o Estado é um grande estimulador e reprodutor das paixões tristes, como diz Espinosa. É por medo dos castigos e esperança das recompensas que o indivíduo submete-se a um poder que o separa da sua própria capacidade de agir e pensar livremente, desejando sua própria servidão (...) sempre realimentado pela repetição da perda da capacidade de criar as próprias condições existenciais de efetuação de suas potências. É assim que tombamos (...) a valores de uma época que, apesar de serem criados por uma determinada sociedade historicamente formada, são publicados e estabelecidos como universais e perenes, enfim, transcendentes ao tempo e ao espaço nos quais emergiram. (FUGANTI, s/d)
\end{abstract}

Assim, a "saúde" do modo como é definida produz subjetividades e por elas é produzida, e ser "paciente" é uma produção desse modelo "saudável", em que se deve acatar as decisões dos especialistas, muitas vezes sem ter sequer a chance de conversar sobre elas, de decidir sobre o próprio corpo.

Segundo Padilha (2006), o olhar sociológico para "a sociedade de consumo" se enriquece quando penetra o espaço da subjetividade. Isto porque, para a autora, existe interdependência entre os espaços privados da subjetividade, mídia, mercadorias de consumo e os espaços da vida pública cotidiana. Ela aponta que as relações entre espaços sociais, sociedade e subjetividade são pouco exploradas nas ciências sociais.

E um fator agravante é que cada época histórica não tem apenas uma estrutura social e práticas culturais particulares, mas diferentes modos de subjetividade, ou seja, cada época tem modos próprios por meio dos quais as experiências individuais são socialmente construídas. (PADILHA, 2006, p. 133)

Padilha (2006) afirma que as análises sobre o consumo pelos aspectos subjetivos podem levar à descoberta de que a vida cotidiana e a cultura do consumo fazem emergir novas identificações, algo que ultrapassa a identidade de classe, de gênero ou regionais. Então o consumo deve ser tratado como uma produção da sociedade e do eu, sendo uma apropriação de códigos, estilos e modas feita no interior de cada indivíduo, nos espaços sociais. 
Do mesmo modo que a autora afirma ser o shopping center um lugar não apenas de consumo, mas também de construção de identidade, entendo ser o hospital um lugar onde se constrói a identidade "paciente", que está sempre relacionada à necessária adesão ao tratamento, seja ele qual for.

O hospital também tem seus códigos, seus discursos e até mesmo seu marketing. No hospital público em atuei, havia uma grande preocupação com a imagem, o uso da marca e a publicidade do Instituto, apesar de ser um hospital público.

Além disso, segundo Lopes (2009), o neoliberalismo como forma de vida do presente, institui certas normas não só com a finalidade de posicionar os sujeitos dentro de uma rede de saberes, como também para que se mantenham presentes em redes sociais e de mercado. Para a autora, todos estamos de uma alguma forma sendo conduzidos por determinadas práticas e regras implícitas que nos levam a entrar e permanecer no jogo econômico.

Lopes (2009) afirma ser possível apontar pelo menos duas grandes regras que operam nesse jogo neoliberal. A primeira regra é manter-se sempre em atividade, não é permitido que ninguém pare ou fique de fora, que ninguém deixe de se integrar nas malhas que dão sustentação aos jogos de mercado "e que garantem que todos, ou a maior quantidade de pessoas, sejam beneficiados pelas inúmeras ações de Estado e de mercado".

A segunda regra é que todos devem estar incluídos, mas em diferentes níveis de participação, nas relações que se estabelecem entre Estado e população, públicos/ comunidades e mercado. Para a autora, não se admite que alguém perca tudo ou fique sem jogar, já que ao estarem incluídas nos grupos, nos registros oficiais, nos hospitais, no mercado de trabalho, nas cotas de bolsa-assistência, na escola, etc., as pessoas tornam-se alvos fáceis das ações do Estado. Trata-se de ações que visam a conduzir as condutas humanas dentro de um jogo com regras definidas, no interior dos distintos e dos muitos grupos sociais.

Assim, problematizar o "ser paciente" é problematizar como essa concepção de "saúde" que não é natural e sim produzida socialmente, produz também subjetividade. Muitas vezes nós desejamos, pedimos por mais saúde e mais hospitais, ainda que o hospital seja um lugar triste, de paixões tristes. A vida que é garantida e, não somente isso, que é afirmada como um dever nos discursos e práticas de saúde contemporâneos, não é a mesma vida defendida por Espinosa, quando fala sobre as paixões alegres, sobre a vida como alegria, como possibilidade de ser afetado, em que um indivíduo "é antes de mais nada uma essência singular, isto é, um grau de potência" (DELEUZE, 2002, p. 33). 
Essa forma de ver a vida naquilo que ela tem de forte, potente e alegre, valorizando uma vida ativa e a manifestação da diferença, a potência e singularidade que cada um de nós tem - e até mesmo a dor como algo que pode tornar-nos ainda mais fortes - em muito diferencia da vida a que temos obrigação de viver segundo os discursos de "saúde" atuais, incentivadores de práticas pastorais. A vida garantida pela atual concepção de saúde está pautada em generalizações, universalidades, modelos, sendo sempre afirmada como um direito e, obviamente, não menos como uma obrigação, não sendo de modo algum a vida que se quer viver, mas a vida que se deve viver.

A vida como dever está presente nos discursos da área da saúde, sendo enfatizada e valorizada por suas generalizações, principalmente no que ela tem de universal: "todos têm direito à vida", "todos têm direito à saúde", "a saúde é dever do Estado e da família", como consta na Lei 8.080 de 19 de setembro de 1990, "O dever do Estado não exclui o das pessoas, da família, das empresas e da sociedade" (BRASIL, 1990).

Para Fuganti,

Toda essa visão da lei, do bem comum e da obediência a um plano de organização de direitos e deveres que normatizariam as condutas e levariam a uma pretensa ordem universal, numa palavra, tudo o que constitui a atitude Moral propriamente dita na relação do indivíduo com a sociedade, precisa ser claramente distinguida de uma outra atitude, a postura a que chamamos Ética. (FUGANTI, s/d).

Assim, a valorização da vida que tanto se defende nas concepções e práticas de saúde atuais é um modo de desvalorizar a vida ativa e, paradoxalmente, evitar a morte. Esse modo de viver em que o Estado deve ser o garantidor da vida, aquele que "faz viver" padronizando o considerado correto, produz dominação e sujeição, de acordo com as análises de Fuganti. Não à toa o hospital muitas vezes nega a possibilidade de escolha de um adolescente sobre o seu próprio corpo. No entanto, diferente de uma postura moral que define o que fará bem ou mal às crianças e adolescentes, pautada em concepções de mal e bem moralizadoras, existe a necessidade de que haja uma postura ética que respeite as diferenças e valorize a possibilidade de escolha das pessoas acerca de seus próprios corpos e de suas vidas. Uma nova ética que, segundo Fuganti,

É a partir de outro lugar que não o da dominação e da sujeição, é a partir de um topos ocupado pela potência de afirmar as próprias diferenças constituintes dos seres ou ponto de vista da vida em processo de diferenciação, que o modo de vida ético se instala. (FUGANTI, s/d) 
Em minha opinião, a recusa à amputação por parte dos adolescentes, crianças e suas famílias, pode expressar singularidades e desejos, subvertendo o lugar de obediência que o "paciente" deve ocupar, principalmente quando se trata de doença grave que ameaça a vida.

Subverter, nesse contexto, é também aceitar o desafio de não naturalizar, mas analisar as experiências vivenciadas no hospital de câncer, de modo que analisar possa "constituir palavra de desordem, de invenção, de conexão, de transgressão (...) (RODRIGUES, 2012, p. 39)

\section{Considerações finais}

A amputação de um membro do corpo de crianças e adolescente é uma prática médica freqüente na área oncológica. No âmbito da saúde pública, observei que muitas famílias em acompanhamento vivenciam um extremo sofrimento diante do adoecimento de seus filhos e do tratamento, que muitas vezes envolve cirurgias mutilantes, quimioterapia e radioterapia, provocando dores indescritíveis e problemas de difícil enfrentamento. Nesse contexto, a recusa ao tratamento por parte das famílias de crianças e adolescentes, assim como por parte dos próprios adolescentes, também acontece com freqüência.

Muitas vezes, a resposta da equipe de saúde à resistência ao tratamento é a afirmação de diagnósticos colocados como verdades absolutas, ou mesmo de desqualificações das famílias pobres, vistas como incapazes de cuidar de seus filhos. Tais desqualificações podem resultar em encaminhamentos ao conselho tutelar ou à justiça.

No entanto, neste artigo buscamos questionar a identidade paciente enquanto aquele que deve necessariamente acatar os diagnósticos dados, sem nenhuma chance de recusa. Buscamos analisar o hospital enquanto lugar da cura e as relações de saber/poder que atravessam a lógica médico-paciente. Entendemos que a produção da identidade "paciente" passa pela lógica do consumo na sociedade capitalista e também pelo discurso científico com suas verdades inquestionáveis.

É desse modo que a identidade paciente, como aquele que não pode decidir sobre o seu próprio corpo é forjada. A recusa ao tratamento não é aceita como uma diferença legítima, por ser entendida como anormalidade, doença, perigo, já que as pessoas devem apenas aceitar passivamente as prescrições médicas.

No entanto, entendo que a recusa ao tratamento pode expressar a afirmação de singularidades, desejos, culturas, e diferentes modos de ver a vida que não se limitam às práticas médicas. Ao invés de compreender como doença mental as resistências, cabe problematizar as rotinas hospitalares, as relações 
entre profissionais de saúde e os usuários do SUS, assim como as culturas das crianças e famílias, que podem não corresponder aos saberes científicos, o que não lhes retira a legitimidade.

A recusa ao tratamento enquanto afirmação da diferença deve ser considerada como possibilidade legítima diante das inúmeras regras impostas cotidianamente na área da saúde, em detrimento da afirmação da identidade "paciente", enquanto aquele que deve necessariamente obedecer.

\section{Referências}

BRASIL. Lei n. 8.080, de 19 de setembro de 1990. Lei Orgânica da Saúde. Diário Oficial [da] República Federativa do Brasil, Brasília, DF: Presidência da República.

COIMBRA, C.; NASCIMENTO, M. L. O efeito Foucault: desnaturalizando verdades, superando dicotomias. Revista Psicologia: Teoria e Pesquisa, Brasília, DF, v. 17, n. 3, p. 1-5, set. 2001.

COIMBRA, C; NASCIMENTO, M. L. Sobreimplicação: práticas de esvaziamento político? In: ARANTES, E. M.; NASCIMENTO, M. L.; FONSECA, T. M. G. (Orgs.). Práticas PSI inventando a vida. Niterói: EdUFF, 2007, p. 27-38.

DELEUZE, G. Espinosa: filosofia prática. São Paulo: Escuta, 2002. 144 p.

FOUCAULT, M. Microfísica do poder. Org. e trad. de Roberto Machado. Rio de Janeiro: Graal, 1979. 295 p.

FOUCAULT, M. “O sujeito e o poder”. In: DREYFUSS, H.; RABINOW, P. Michel Foucault uma trajetória filosófica: para além do estruturalismo e da hermenêutica. Rio de Janeiro: Forense Universitária, 1995, (p. 231-249).

FOUCAULT, M. Em defesa da sociedade. São Paulo: Martins Fontes, 2002.

FOUCAULT, M. Ditos e escritos, volume V: ética, sexualidade, política. 3. ed. Rio de Janeiro: Forense Universitária, 2012. 325 p.

FISCHER, R. M. Trabalhar com Foucault: arqueologia de uma paixão. Belo Horizonte: Autêntica, 2012. 168 p.

FUGANTI, L. Ética como potência e moral como servidão. In: https://pt.scribd.com/ document/68558526/Fuganti-A-Etica-como-potencia-e-a-Moral-como-servidao-completo Acesso em: 12 de jun. 2017.

LOPES, M. C. Políticas de inclusão e governamentalidade. Educação \& Realidade, Porto Alegre, v. 34, n. 2, p. 153-169, mai/ago, 2009. 
LOURAU, R. René Lourau na UERJ- 1993. Análise Institucional e Práticas de Pesquisa. Rio de Janeiro: Editora da UERJ, 1993. Mnemosine. v. 3, n. 2, 2007. Disponível em http://www. mnemosine.cjb.net/mnemo/index.php/mnemo/issue/view/20 Acesso em: 22 ago. 2015.

MACHADO, R. Foucault, a ciência e o saber. 3. ed. Rio de Janeiro: Zahar, 2007.

NIETZSCHE, F. W. Genealogia da Moral: uma polêmica. Tradução, notas e posfácio Paulo César de Souza. São Paulo, Companhia das Letras, 1998.

NIETZSCHE, F. W. Além do bem e do mal: prelúdio a uma filosofia do futuro. Tradução, notas e posfácio Paulo César de Sousa. São Paulo: Companhia das Letras, 2005. 247 p.

OLIVEIRA, J. Para uma ética da amizade em Friedrich Nietzsche. Rio de Janeiro: 7 letras, 2011. 200 p.

PADILHA, V. Shopping center: a catedral das mercadorias. São Paulo: Boitempo, 2006. 209 p.

REIS, E. O que se quer quando se pede por justiça? Sobre o espírito de vingança e a atualidade do homem do ressentimento. 2013. Tese (Doutorado em Psicologia) - Curso de Pós-graduação em Psicologia, Universidade Federal Fluminense. Niterói, RJ.

RODRIGUES. H. Analisar. In: FONSECA, T.; NASCIMENTO. M. L.; MARASCHIN, C. (Orgs.). Pesquisar na diferença/ um abecedário. Porto Alegre: Sulina, 2012, p. 37-39.

SCHEINVAR, E. O feitiço da política pública: escola, sociedade civil e direitos da criança e do adolescente. Rio de Janeiro: Lamparina; Faperj, 2009.

Submissão em: 16/07/2016

Revisão em: 27/12/2016

Aceite em: 12/06/2017

Kassia de Oliveira Martins Siqueira é assistente social e especialista em Serviço Social e Saúde. Graduanda em Filosofia pela Universidade do Estado do Rio de Janeiro. Mestre e doutoranda em Políticas Públicas e Formação Humana pela Universidade do Estado do Rio de Janeiro. Endereço: UERJ. Programa de Pós-graduação em Políticas Públicas e Formação Humana. Rua São Francisco Xavier, n ${ }^{\circ}$ 524, Pavilhão João Lyra Filho, $12^{\circ}$ andar, Bloco F, Sala 12.111, Maracanã, Rio de Janeiro/RJ, Brasil. CEP 20550900. E-mail: kassia_siqueira@yahoo.com.br 